\title{
Characterization of Ceramics Coatings Processed by Sol-Gel for Cutting Tools
}

\author{
Bruna Aparecida Rezende ${ }^{1}(0)$, Anderson Júnior dos Santos ${ }^{2}\left(0\right.$, Marcelo Araújo Câmara ${ }^{2}(\mathbb{D}$, \\ Denilson José do Carmo ${ }^{3,4}$, Manuel Houmard ${ }^{5}\left(0\right.$, Alessandro Roger Rodrigues ${ }^{6}$ \\ and Juan Carlos Campos Rubio 1,2,*(D) \\ 1 Department of Production Engineering, Universidade Federal de Minas Gerais, Avenida Antônio Carlos, \\ 6627, Pampulha, Belo Horizonte CEP 31270-901, MG, Brazil; brunarezende12@yahoo.com.br \\ 2 Department of Mechanical Engineering, Universidade Federal de Minas Gerais, Avenida Antônio Carlos, \\ 6627, Pampulha, Belo Horizonte CEP 31270-901, MG, Brazil; ndersonsantos@hotmail.com (A.J.d.S.); \\ marcelocamara@demec.ufmg.br (M.A.C.) \\ 3 Centro Tecnológico de Fundição Marcelino Corradi-SENAI-CETEF-Itaúna CEP 35680-270, MG, Brazil; \\ djcarmo@fiemg.com.br \\ 4 Faculty of Engineering, Universidade de Itaúna, Itaúna CEP 35680-142, MG, Brazil \\ 5 Department of Materials and Construction Engineering, Universidade Federal de Minas Gerais, Avenida \\ Antônio Carlos, 6627, Pampulha, Belo Horizonte CEP 31270-901, MG, Brazil; mhoumard@ufmg.br \\ 6 Department of Mechanical Engineering, Universidade de São Paulo, Av. Trabalhador São-Carlense, 400, \\ Centro, São Carlos CEP 13566-590, SP, Brazil; roger@sc.usp.br \\ * Correspondence: juan@ufmg.br; Tel.: +55-31-3409-3505
}

Received: 24 September 2019; Accepted: 7 November 2019; Published: 14 November 2019

\begin{abstract}
In order to obtain better cutting tool performance, the coatings appear as an alternative in the machining process. The goal of the coating is to improve tribological conditions in the chip-tool and tool-workpiece interfaces. On the other hand, the use of coated tools decreases the wear of the tools. This study discusses the ceramic coatings characterization deposited in WC tools. The $\mathrm{Al}_{2} \mathrm{O}_{3}$ and $\mathrm{TiO}_{2}$ films present properties such as thermal stability, chemical inertia, high hardness, and good mechanical properties. These coatings were prepared by sol-gel technology. The results indicated that the multilayer coating presents better adhesion on the substrate. Moreover, lower coefficients of friction were found for the coated tools. The analysis of variance (ANOVA) was used to evaluate the influence of the cutting parameters and tool coating on the cutting force. The lower cutting force was obtained using the multilayer-coated tool. Thus, the sol-gel method appears as a novel technique to deposit coating in the WC tools to improve their performance.
\end{abstract}

Keywords: tools coatings; sol-gel; $\mathrm{TiO}_{2} ; \mathrm{Al}_{2} \mathrm{O}_{3}$; cutting force

\section{Introduction}

The machining is one of the most applicable processes in the manufacture of metals. For this reason, different researchers have focused their efforts on tool improvement and optimization of cutting parameters [1]. Indeed, it is necessary to choose the cutting parameters correctly to decrease the wear and consequently increase the tool life. Tooptong et al. [2] affirm that the rise in the cutting temperature due to the increase of the cutting speed leads to the degradation of the cutting tool material. Thus, different coating techniques have been developed to improve the resistance of the tool, such as chemical vapor deposition (CVD) [3], physical vapor deposition (PVD) [4,5] and sol-gel [6,7], allowing the fabrication of different coating materials.

Astakhov [8] affirms that the purpose of the coatings is to improve the tribological conditions at the chip-tool and tool-workpiece interfaces, and finally, to contribute to improvement of the process 
as in the study of Rubio [9]. Therefore, it can be assured that the improvement of the tribological characteristics of cutting tools using coatings is not only technically efficient but also economically viable [10]. Factors, such as the adhesion of the coating to its substrate, hardness, and residual stresses modify the performance of the coating [11]. Despite there being few pieces of work about sol-gel coating on cutting tools, satisfactory results have been obtained using this technology. Chen et al. [6] used the sol-gel as an auspicious technique to coat cutting tools and showed that the coated tools presented less flank wear than the uncoated one. Similarly, positive results using this sol-gel coating method were also observed in the work of Rubio et al. [12]. Moreover, Tlili et al. [13] studied the wear resistance of the stainless steel using alumina coating deposited by the sol-gel method. In this work, the pin-disc test established that the alumina layers improve the tribological behavior of the stainless steel substrate, and reduce its wear and damage.

The main advantage of the sol-gel process is the possibility to deposit and process the solid oxide coating at low temperatures [14-16]. Using this method, it is also possible to prepare a film for technological applications at a low cost [17]. In this research, $\mathrm{Al}_{2} \mathrm{O}_{3}$ and $\mathrm{TiO}_{2}$ coatings will be processed by the sol-gel method and deposited onto tungsten carbide substrate by dip-coating. This one is the most used technique for the deposition of sol-gel film principally because it allows coating materials with complex geometries. Such a technique consists of three main steps: immersion and dwell time, deposition and drainage, and evaporation [18] (Figure 1).

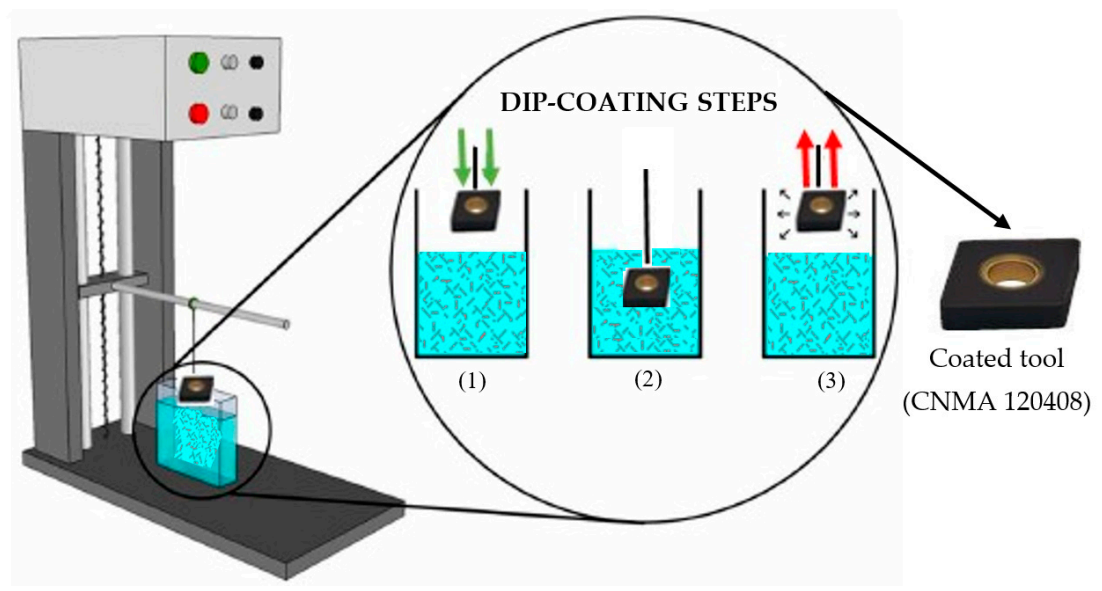

Figure 1. Dip-coating steps: (1) immersion and dwell time, (2) deposition and drainage, and (3) evaporation.

One of the main reasons to use aluminium oxide as a tool coating is because it presents a high wear resistance $[3,19]$. The $\mathrm{Al}_{2} \mathrm{O}_{3}$ is characterized by excellent thermal stability, chemical inertness, relatively high hardness at elevated temperatures, and good mechanical and anti-corrosive properties $[19,20]$. Nevertheless, the main properties of the $\mathrm{TiO}_{2}$ include low cost, high stability, chemical inertness, biocompatibility, and non-toxicity [21]. On the other hand, Du et al. [22] justify the use of this coating on materials such as high-speed steel, because of its considerably low crystallization temperature.

To test the performance of the WC tools coated by the sol-gel method, the compacted graphite iron (CGI) will be machined. This material exhibits hard machining properties. Besides the absence of $\mathrm{MnS}$ and low thermal conductivity, Su et al. [23], mention the presence of hard titanium particles in its composition. On the other hand, at moderate cutting speeds, there is the formation of built-up edge formation, abrasive and adhesive wear [24]. Recently, the CGI turning tests have been studied by many authors, as Tooptong et al. [2]; Abdoos et al. [24]; Yamamoto et al. [25]; Heep et al. [26]. Tooptong et al. [2] investigated the flank wear when turning three cast irons (flake graphite iron (FGI), compacted graphite iron (CGI) and nodular graphite iron (NGI)) under dry conditions. Regardless of the presence of coating on the surfaces of the insert, the authors concluded that the main reason 
for the poor machinabilities (flank wear) of the CGI (and NGI as well) is that the generated cutting temperatures are much higher than for the FGI.

Abdoos et al. [24] evaluated the cutting efforts in CGI turning using different TiAlN coating thicknesses. The results demonstrated that an increase in thickness delays the substrate exposure, which contributes to increasing the tool's life. On the other hand, the thickness influences the tool microgeometry in a way that affects the cutting forces, thermal and mechanical loads in the coating, which can lead to premature tool failures. Thus, it appears necessary to control the coating thickness and identify the optimal one. In this work, the optimal coating thickness was $11 \mu \mathrm{m}$. Besides, Yamamoto et al. [25] evaluated the machining of compacted graphite iron using a new PVD coating family. The TiAlN-based coatings composition (Ti/Al ratio), architecture (mono vs. multilayer), and thickness parameters were studied in this work. The application of the optimized coating resulted in a 40-60\% improvement of the cutting tool life under the finishing turning of CGI. Heep et al. [26] studied the CGI turning using carbon dioxide snow. The main results indicated that the efficient rake face cooling is essential for the reduction of thermal tool loads and has a significant effect on the crater wear behavior. Moreover, the wear development on the flank face can be further reduced by targeted flank face cooling.

Therefore, the present paper aims to characterize the sol-gel multilayer and $\mathrm{Al}_{2} \mathrm{O}_{3}$ coated tools used in CGI turning. The coatings were characterized by X-ray diffraction (XRD), scanning electron microscope (SEM), energy-dispersive X-ray spectroscopy (EDS) and scratch test. The friction coefficients were collected for the tribological pairs using a tribometer. Finally, different cutting conditions have been used during the machining tests to measure the corresponding cutting force and the results were treated using the analysis of variance (ANOVA).

\section{Materials and Methods}

\subsection{Workpiece and Cutting Tools}

The material used for the turning tests was CGI. The diameter of the cylinder is 69 and $300 \mathrm{~mm}$ of length. The mechanical properties are summarized in Table 1.

Table 1. Mechanical properties established by ASTM-A 842/85 [27].

\begin{tabular}{cc}
\hline Properties & Grade 350 \\
\hline Tensile strength limit (MPa) & 350 \\
Flow limit $(\mathrm{MPa})$ & 245 \\
Elongation $50 \mathrm{~mm}(\%)$ & 1.0 \\
\hline
\end{tabular}

The WC tools used were K10 class, for cast iron machining, code CNMA 120408 HTi10-Mitsubishi (Tokyo, Japan). The tools used were the uncoated one, the one coated with aluminium oxide (three layers) and the multilayer-coated one (one layer of the titanium dioxide and three layers of the aluminium oxide, respectively). The $\mathrm{TiO}_{2}$ layer was used to improve the adhesion to the substrate. The $\mathrm{Al}_{2} \mathrm{O}_{3}$ was used to improve the resistance to wear.

\subsection{Cleaning of the Cutting Tools}

All inserts were subjected to an ultrasonic acetone bath for $10 \mathrm{~min}$ and methanol for $5 \mathrm{~min}$ before coating them by the sol-gel deposition processes.

\section{3. $\mathrm{TiO}_{2}$ Coating}

The coating was processed by sol-gel technology and deposited by dip-coating with a withdrawal speed of $\sim 3.33 \mathrm{~mm} / \mathrm{s}$. In this work, the reagents were tetraisopropyl orthotitanate (TIPT), deionized water $\left(\mathrm{H}_{2} \mathrm{O}\right)$, hydrochloric acid $(\mathrm{HCl}$, purity of $36 \%)$, and absolute ethanol as solvent. This solution is characterized by a TIPT concentration of $0.4 \mathrm{~mol} / \mathrm{L}$, a molar ratio water/TIPT of 0.82 , and a pH of 1.27 
in agreement with a previous work written by Houmard et al. [28]. The ageing process of the sol-gel solution was at least two weeks in order to let the hydrolysis, and condensation reactions occurring. This process leads to a thicker film after the dip-coating step. The coating was dried at $100{ }^{\circ} \mathrm{C}$ for 15 min before the other depositions.

\section{4. $\mathrm{Al}_{2} \mathrm{O}_{3}$ Coating}

The $\mathrm{Al}_{2} \mathrm{O}_{3}$ coating was processed by sol-gel technology and deposited by dip-coating with a withdrawal speed of $\sim 0.4 \mathrm{~mm} / \mathrm{s}$. The reagents were aluminium isopropoxide (IPA), deionized water $\left(\mathrm{H}_{2} \mathrm{O}\right)$, and nitric acid $\left(\mathrm{HNO}_{3}\right)$. The IPA: $\mathrm{H}_{2} \mathrm{O}: \mathrm{HNO}_{3}$ molar ratio used was 1:60:0.10. The deionized water was heated at $85^{\circ} \mathrm{C}$; reaching this temperature the nitric acid was inserted; and then, the aluminium precursor (powder compound) was added slowly. The solution was heated at $90^{\circ} \mathrm{C}$ for $24 \mathrm{~h}$. The $\mathrm{Al}_{2} \mathrm{O}_{3}$ solution was prepared in agreement with Chen et al. procedure [6]. The purpose of using 3 layers was to obtain an appropriate thickness for the machining test. The $\mathrm{Al}_{2} \mathrm{O}_{3}$ coating was deposited performing three immersions of the tool. Each layer had been dried at $100^{\circ} \mathrm{C}$ for $15 \mathrm{~min}$ between each deposition step and finally, the tools were heat-treated at $450^{\circ} \mathrm{C}$ for $1 \mathrm{~h}$ to favor the densification of the sol-gel films.

\subsection{Characterization of the Coatings}

The $\mathrm{Al}_{2} \mathrm{O}_{3}$ coatings and multilayer coatings were characterized using the scanning electron microscope (SEM) Quanta FEG 3D model (FEI Company, Hillsboro, USA). This equipment includes the energy dispersive spectroscopy (EDS) analysis as well. The structure of the resulting $\mathrm{x}-\mathrm{Al}_{2} \mathrm{O}_{3}$ coating was characterized by X-ray diffraction (XRD) using a Rigaku diffractometer (model D/max-last IV, Rigaku Corporation, Woodlands, TX, USA) operated at $15-50 \mathrm{kV}$ and monochromatized with $\mathrm{Cu}-\mathrm{K} \alpha$ radiation where the scanning speed was 4 degrees per minute.

\subsection{Scratch Test}

The tests were performed to characterize the adhesion of the coatings. The equipment used was the sclerometer developed by the Laboratory of Tribology and Materials of the Federal University of Uberlândia (Brazil). The test consists of scratching the coated sample with a Rockwell indenter (Materialprüfungsamt Nordrhein-Westfalen (MPA NRW), Dortmund, Germany). Its load was progressively increased at a rate of $12 \mathrm{~N} / \mathrm{mm}$, reaching the maximum load of $50 \mathrm{~N}$, a distance of $4 \mathrm{~mm}$ and speed of $0.010 \mathrm{~mm} / \mathrm{s}$.

\subsection{Tribometer Test}

The mean roughness values $\left(R_{\mathrm{a}}\right)$ of the samples are measured according to the norm ASTM G99-05 [29]. They do not exceed $0.8 \mu \mathrm{m}$. The Tribometer Microtest, model SMT-A/0100 (Microtest S.A., Madrid, Spain) was used to determinate the coefficients of friction. The values were collected by Nanovea Tribometer software version 1.5.3 (Micro Photonics Inc., Allentown, USA). The normal load applied was $5 \mathrm{~N}$ and the sliding speed $64.62 \mathrm{~m} / \mathrm{min}$. The sliding distance was $150 \mathrm{~m}$. The tests were made under dry conditions at room temperature.

\subsection{Cutting Force}

For the acquisition of the cutting force signals the Kistler dynamometer-Model 9272 (Winterthur, Switzerland), with the National Instruments USB-6366 data acquisition board (Austin, TX, USA) and the software NI LabView Signal Express 2013 was used.

\subsection{Experimental Setup}

Dry turning tests were made on a computer numerical control (CNC) lathe (5.5 kW power and maximum rotational speed of $3500 \mathrm{rpm}$. The cutting parameters used are shown in Table 2. The full 
factorial experiment was conducted twice, which means that 36 experiments were realized two times each. The cutting depth $\left(a_{\mathrm{p}}\right)$ used was $1 \mathrm{~mm}$ for all experimental conditions.

Table 2. Parameters and their levels used during the turning experiments.

\begin{tabular}{cc}
\hline Parameters & Levels \\
\hline Tool & Uncoated; $\mathrm{Al}_{2} \mathrm{O}_{3}$ coated tool; Multilayer coated tool \\
Cutting speed $\left(V_{c}\right)$ & $125 ; 175 ; 225 ; 275 \mathrm{~m} / \mathrm{min}$ \\
Feed $(f)$ & $0.1 ; 0.2 ; 0.3 \mathrm{~mm} / \mathrm{rev}$ \\
\hline
\end{tabular}

\section{Results and Discussions}

\subsection{X-ray Diffraction}

The X-ray diffraction of the aluminium oxide is illustrated in Figure 2. Figure 2a shows the sample without heat treatment. It was observed that the diffraction peaks coincided with the boehmite phase- $\mathrm{AlO}(\mathrm{OH})$. Besides, Figure $2 \mathrm{~b}$ displays the sample after heat treatment of $450{ }^{\circ} \mathrm{C}$ indicating that this phase disappeared, highlighting some peaks which coincided with the $\mathrm{y}^{-} \mathrm{Al}_{2} \mathrm{O}_{3}$ pattern. These results indicated that the de-hydroxylation of the boehmite phase occurred, which transformed into $\mathrm{\gamma}-\mathrm{Al}_{2} \mathrm{O}_{3}$, as expected at this temperature. Indeed, according to Chen et al. (2000) [6], the $\mathrm{\gamma}-\mathrm{Al}_{2} \mathrm{O}_{3}$ phase consolidates from $380^{\circ} \mathrm{C}$. The broad peaks are due to the small size of the nanocrystals formed during the sol-gel deposition. In particular, the broad band observed between $20^{\circ}$ and $43^{\circ}$ in Figure $2 \mathrm{~b}$ results from the overlapping of three small peaks of the $\mathrm{\gamma}-\mathrm{Al}_{2} \mathrm{O}_{3}$ phase indicated by the literature (Joint Committee on Powder Diffraction Standards (JCPDS) card number 00-029-0063 illustrated in Figure 2b).

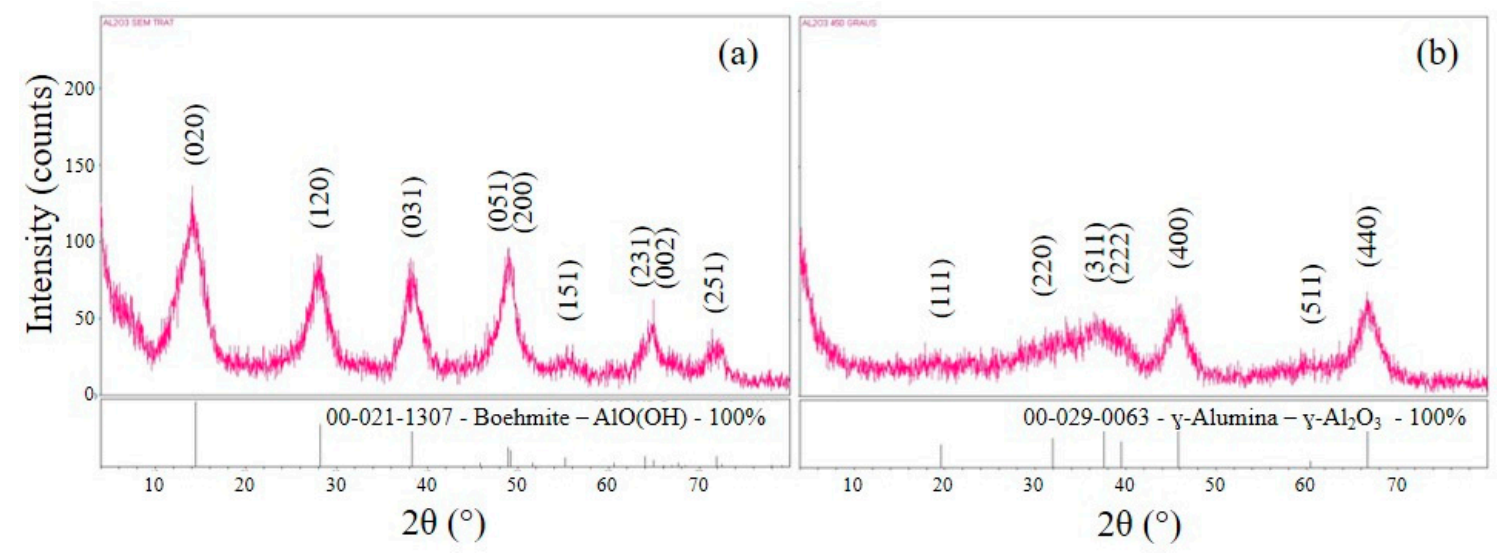

Figure 2. (a) X-ray diffraction for untreated and (b) heat treated samples. Patterns of JCPDS card numbers 00-021-1307 and 00-029-0063, corresponding respectively to the Boehmite and $\mathrm{y}-\mathrm{Al}_{2} \mathrm{O}_{3}$ phases, are also represented.

\subsection{Characterization of Aluminium Oxide Coating}

Figure $3 \mathrm{~b}$ presents an SEM image of the aluminium oxide coating together with the EDS spectra taken in the substrate and coated regions of the tool. The $\mathrm{Al}_{2} \mathrm{O}_{3}$ coating was obtained after three immersions. The coating reflects good adhesion to the substrate. Figure $3 a, c$ details the EDS spectra of the substrate and coated regions of the tool. According to EDS taken from the substrate region, relevant peaks of the chemical elements $\mathrm{W}, \mathrm{C}, \mathrm{O}$, and $\mathrm{Co}$ from the commercial insert are observed. In the coated region, principally peaks corresponding to $\mathrm{Al}$ and $\mathrm{O}$ are present, confirming the presence of the $\mathrm{Al}_{2} \mathrm{O}_{3}$ coating on the surface of the tool. Using the EDS, it is worth noting that when the electron beam hits the material surface, the $\mathrm{X}$-rays emitted by the electrons have enough energy to cross a 
material thickness of about $5 \mu \mathrm{m}$. As a result, it is obvious that the EDS spectrum from the coated region should indicate the presence of the elements present in the WC commercial insert composition.

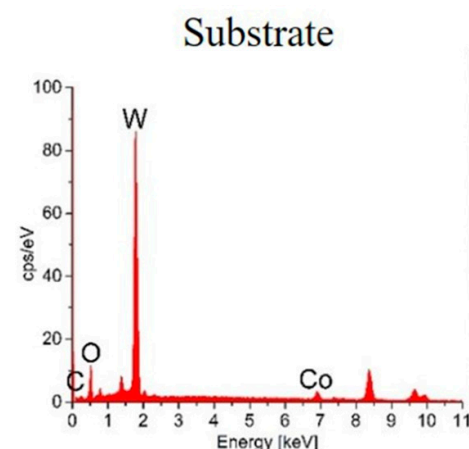

(a)

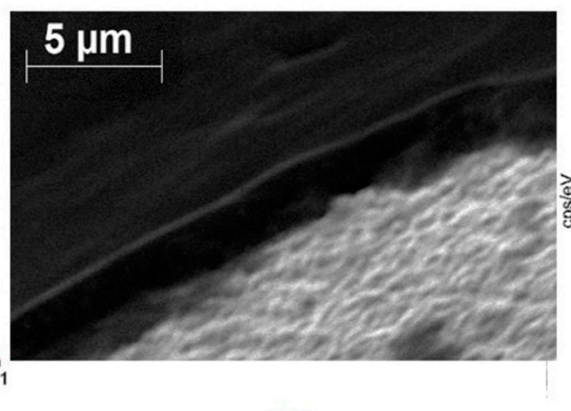

(b)

\section{Coating}

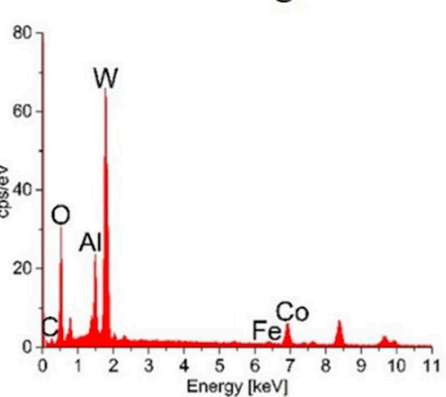

(c)

Figure 3. (a) EDS spectrum from the substrate region of the tool, (b) SEM image of the $\mathrm{Al}_{2} \mathrm{O}_{3}$ coating, and (c) EDS spectrum from the $\mathrm{Al}_{2} \mathrm{O}_{3}$ coated region of the tool.

\subsection{Characterization of Titanium Dioxide Coating}

Figure 4 shows an SEM image of the titanium dioxide coating together with the EDS spectra taken in the substrate and coated regions of the tool. The EDS analysis demonstrates the same peaks corresponding to the chemical element from the substrate as previously. However, from the coating region, peaks of $\mathrm{Ti}$ and $\mathrm{O}$ are present, confirming the deposition of the $\mathrm{TiO}_{2}$ coating. One more time, the peaks of the elements present in the WC insert appear due to the thin thickness of the $\mathrm{TiO}_{2}$ film. Since the $\mathrm{TiO}_{2}$ layer was used only to improve the adhesion with the substrate. The crystalline structure of the $\mathrm{TiO}_{2}$ film had not been studied in this work. However, Langlet et al. [30] and Aun et al. [31] used the same sol-gel solution to deposit $\mathrm{TiO}_{2}$ thin films. Despite a possible influence of the material used as a substrate, both studies showed that the film deposited first transforms in the anatase phase and then in the rutile phase when increasing the temperature of the heat treatment. In this work, since the temperature of the heat treatment used is relatively low $\left(450{ }^{\circ} \mathrm{C}\right)$, the $\mathrm{TiO}_{2}$ film deposited from the same sol-gel solution is probably in its anatase phase.

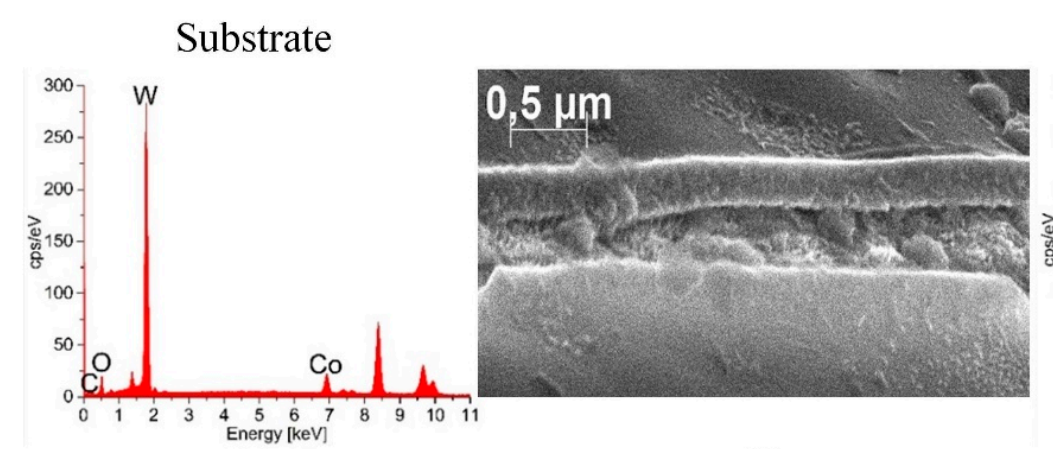

(a) (b)

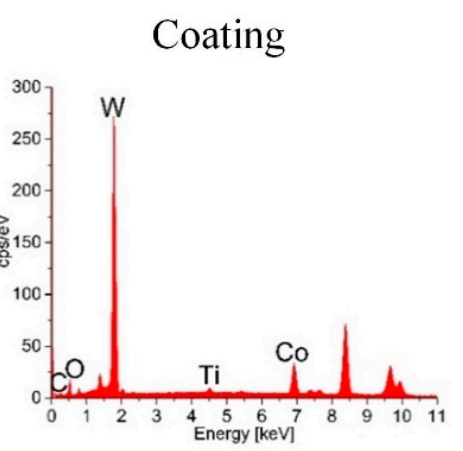

(c)

Figure 4. (a) EDS spectrum from the substrate region of the tool, (b) SEM image of the $\mathrm{TiO}_{2}$ coating, and (c) EDS spectrum from the $\mathrm{TiO}_{2}$ coated region of the tool.

\subsection{Characterization of Multilayer Coating}

Figure 5 shows an SEM image of the multilayer coating deposited on the WC substrate together with the EDS spectra taken in the substrate and coated regions of the tool. It can be seen that the coating showed good adhesion on the WC substrate. Obviously, the EDS spectrum from the substrate showed the same results than the two previous characterizations registered indicating one more time the elements of the WC substrate composition. Nevertheless, the EDS spectrum from the coated region 
exposed additional peaks characteristic of the $\mathrm{Ti}, \mathrm{Al}$ and $\mathrm{O}$ elements, corresponding to the chemistries of the multilayer coating.

\section{Substrate}

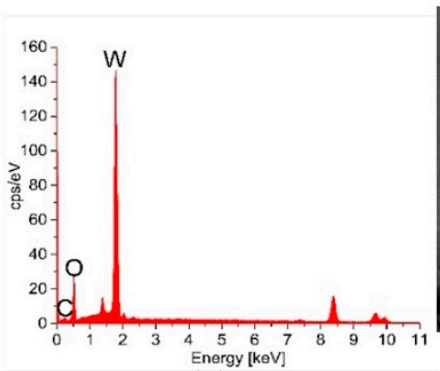

(a)

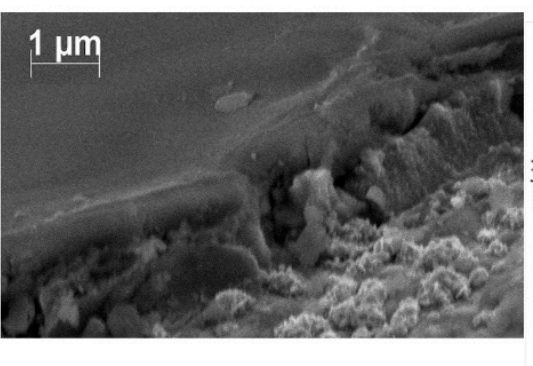

(b)

\section{Coating}

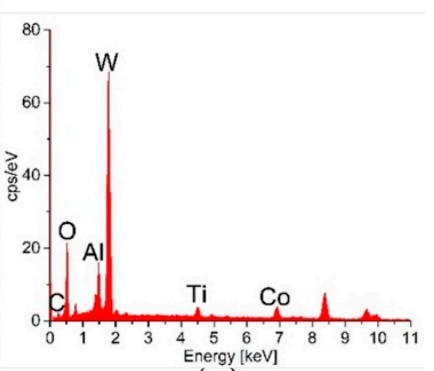

(c)

Figure 5. (a) EDS spectrum from the substrate region of the tool, (b) SEM image of the multilayer coating, and (c) EDS spectrum from the multilayer coated region of the tool.

\subsection{Adhesion by Scratch Test}

Scratch tests were performed for both sol-gel coatings studied in this work (Figures 6 and 7). Points 1 and 2 indicate the regions with and without coating, respectively, for both figures. Due to the presence of peaks corresponding to the $\mathrm{Al}$, $\mathrm{Ti}$, and $\mathrm{O}$ elements the EDS spectra confirm the coatings depositions on the substrates. At the end of the test, the substrate exposure had been observed by SEM, illustrating the coating delamination. From the scratch test curves, the failures start close to $25 \mathrm{~N}$ for the $\mathrm{Al}_{2} \mathrm{O}_{3}$ coating. For the multilayer coating, this event occurs later, between 30 and $40 \mathrm{~N}$. Therefore, it can be assured that the adhesion of the multilayer coating seems to be higher than the one of the $\mathrm{Al}_{2} \mathrm{O}_{3}$ coating.
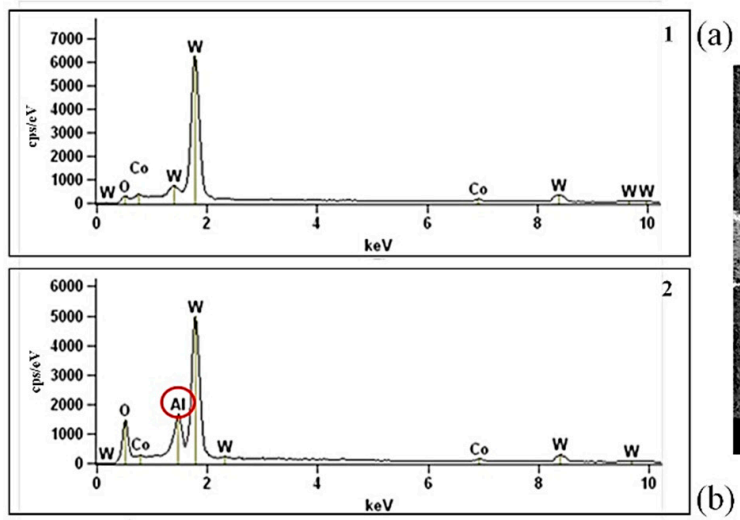

(c)
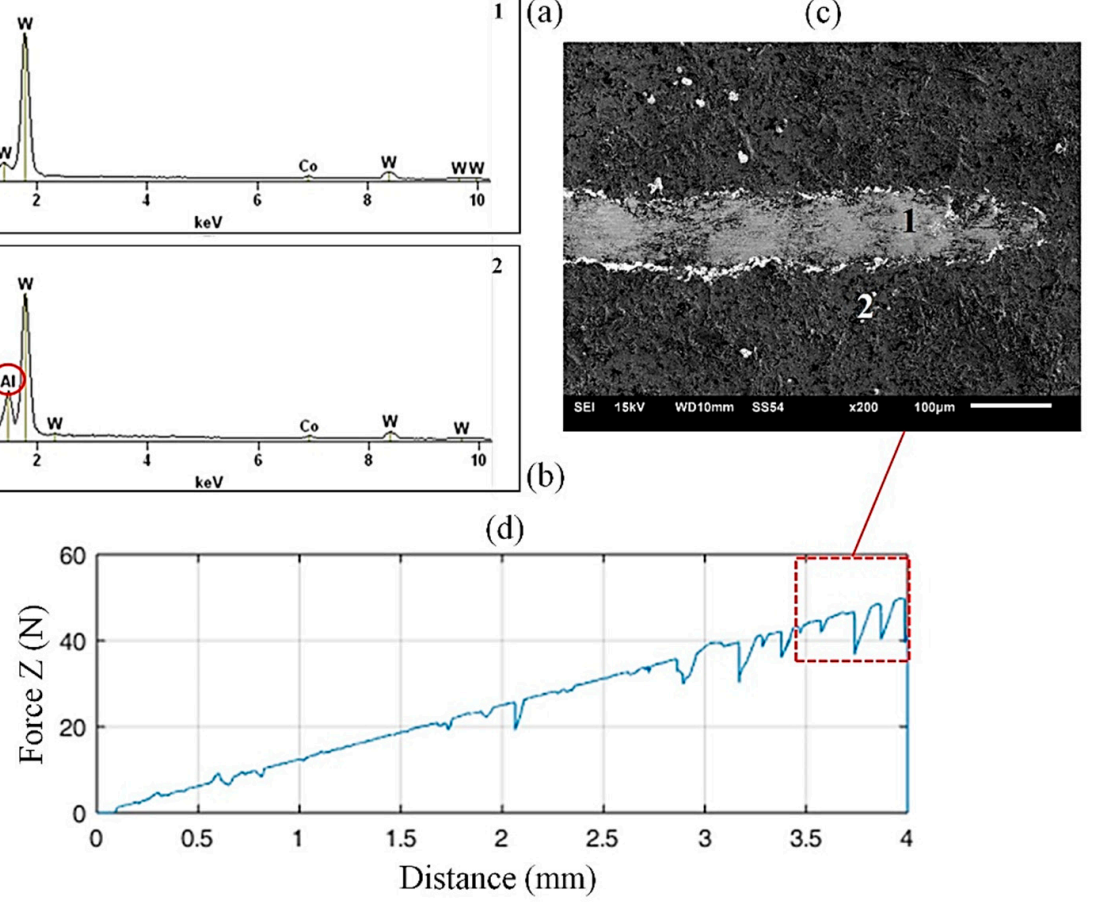

Figure 6. (a) EDS spectrum from the substrate region, (b) EDS spectrum from the $\mathrm{Al}_{2} \mathrm{O}_{3}$ coating, (c) SEM image of the scratch test on the sample with $\mathrm{Al}_{2} \mathrm{O}_{3}$ coating, (1) region without $\mathrm{Al}_{2} \mathrm{O}_{3}$ coating and (2) region with $\mathrm{Al}_{2} \mathrm{O}_{3}$ coating, and (d) Z-force versus distance for scratch test of the $\mathrm{Al}_{2} \mathrm{O}_{3}$ coating. 


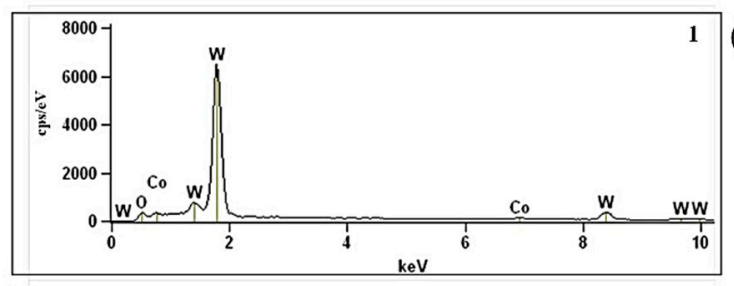

(a)

(c)
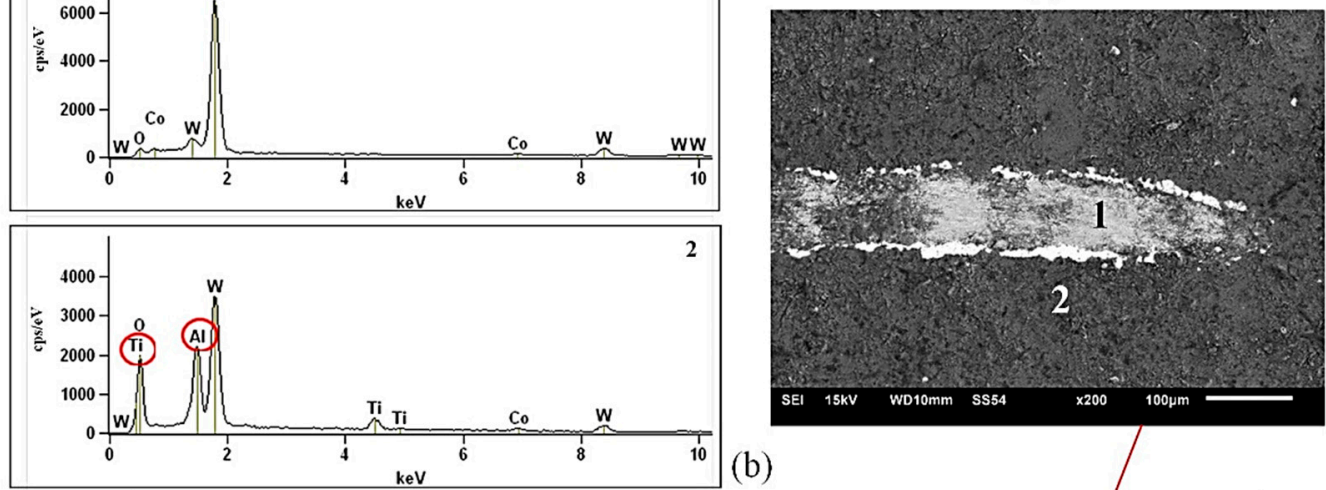

(d)

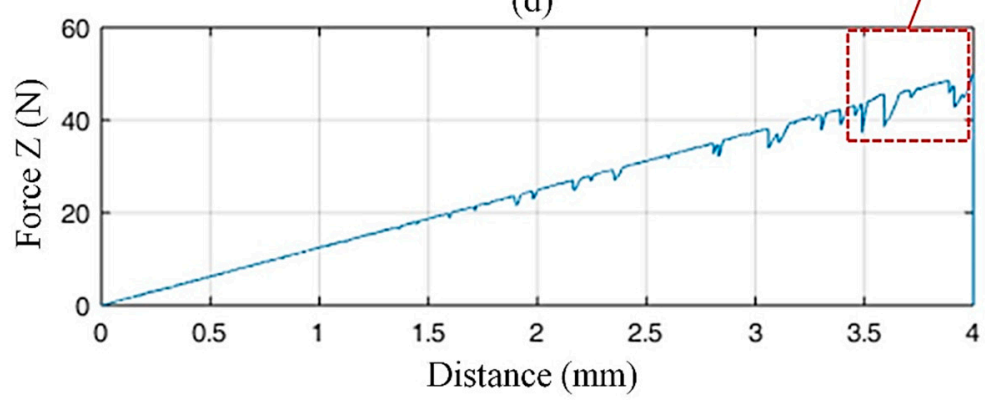

Figure 7. (a) EDS spectrum from the substrate region, (b) EDS spectrum from the multilayer coating, (c) SEM image of the scratch test on the sample with multilayer coating, (1) region without multilayer coating and (2) region with multilayer coating, and (d) Z-force versus distance for the scratch test of the multilayer coating.

\subsection{Coefficient of Friction $(\mu)$}

The behavior of the coefficient of friction $(\mu)$ for uncoated, aluminium oxide and multilayer coating tools versus sliding distance is shown in Figure 8.

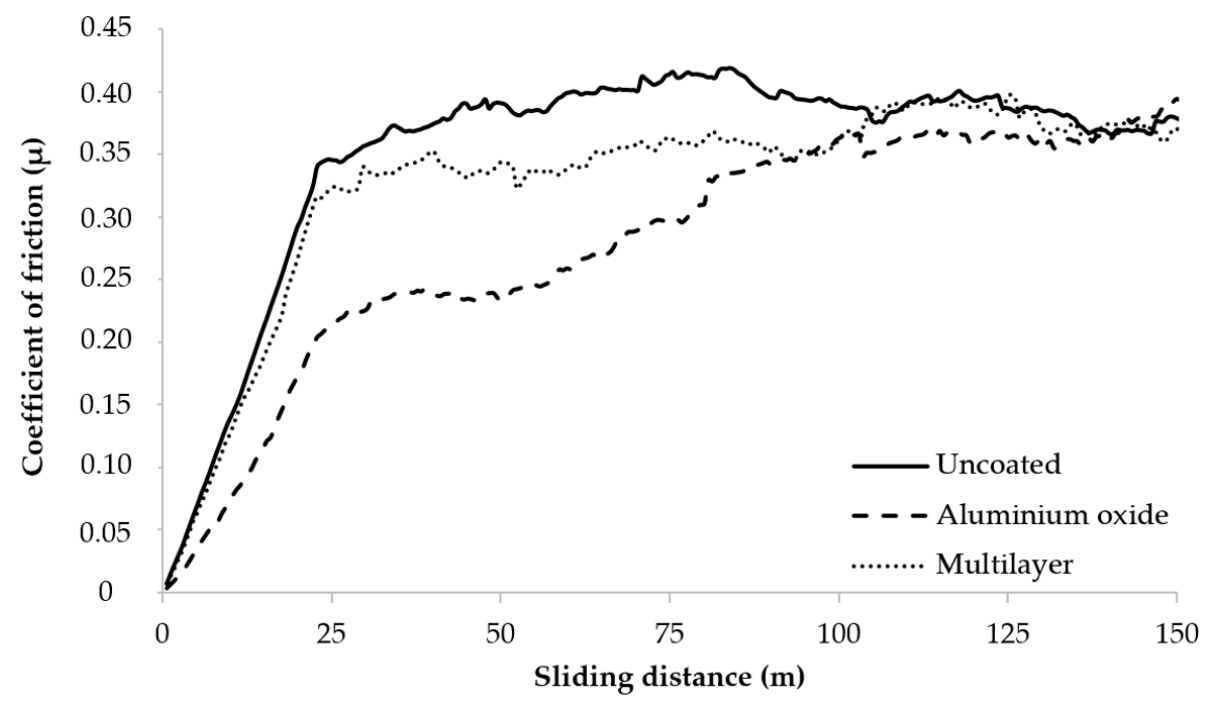

Figure 8. Coefficient of friction versus sliding distance.

The initial friction coefficients of the multilayer and $\mathrm{Al}_{2} \mathrm{O}_{3}$ coated WC are slightly lower than those presented for uncoated WC. This variation is associated with good chemical inertness and lower thermal conductivity of the ceramic coatings. These properties of the ceramic materials were described 
by Kalpakjian and Schimd [32]. Moreover, during the test, the friction properties increase gradually towards a known level to the stabilized friction coefficient. Figure 8 shows that there is a transition period between 25 and $100 \mathrm{~m}$ where the friction coefficient increased for all the tests. During this period, the results suggest that the $\mathrm{Al}_{2} \mathrm{O}_{3}$ and multilayer coatings are acting to minimize the friction coefficient. Thus, the coatings prove its effectiveness against the wear. After the sliding distance of approximately $100 \mathrm{~m}$, a steady-state is achieved, suggesting that the alumina and multilayer oxide coatings had been removed. From this moment, the friction coefficient stays similar for all the tools studied, corresponding to the sliding of the WC substrate against the CGI.

\subsection{Cutting Force}

The measures of the cutting force are reported in Table 3. Turning experiments were realized two times for each combination.

Table 3. Turning experiments realized and their respective cutting force measures.

\begin{tabular}{cccccccccccc}
\hline Test & Tool & $\boldsymbol{V}_{\boldsymbol{c}}$ & $\boldsymbol{f}$ & \multicolumn{2}{c}{ Cutting Force (N) } & Test & Tool & $\boldsymbol{V}_{\boldsymbol{c}}$ & $\boldsymbol{f}$ & Cutting Force (N) \\
\hline 1 & 1 & 1 & 1 & 126.50 & 140.95 & 19 & 2 & 3 & 1 & 108.22 & 134.21 \\
2 & 1 & 1 & 2 & 353.48 & 352.81 & 20 & 2 & 3 & 2 & 333.94 & 322.76 \\
3 & 1 & 1 & 3 & 499.69 & 474.54 & 21 & 2 & 3 & 3 & 487.27 & 485.39 \\
4 & 1 & 2 & 1 & 109.09 & 165.36 & 22 & 2 & 4 & 1 & 121.13 & 95.91 \\
5 & 1 & 2 & 2 & 347.27 & 336.46 & 23 & 2 & 4 & 2 & 322.25 & 308.87 \\
6 & 1 & 2 & 3 & 484.86 & 508.22 & 24 & 2 & 4 & 3 & 511.39 & 452.57 \\
7 & 1 & 3 & 1 & 145.95 & 96.60 & 25 & 3 & 1 & 1 & 157.30 & 126.73 \\
8 & 1 & 3 & 2 & 372.18 & 302.98 & 26 & 3 & 1 & 2 & 360.82 & 336.75 \\
9 & 1 & 3 & 3 & 498.97 & 492.68 & 27 & 3 & 1 & 3 & 502.31 & 482.00 \\
10 & 1 & 4 & 1 & 118.15 & 103.74 & 28 & 3 & 2 & 1 & 109.44 & 129.72 \\
11 & 1 & 4 & 2 & 338.06 & 326.79 & 29 & 3 & 2 & 2 & 276.90 & 320.82 \\
12 & 1 & 4 & 3 & 493.43 & 478.78 & 30 & 3 & 2 & 3 & 451.72 & 492.45 \\
13 & 2 & 1 & 1 & 135.46 & 152.02 & 31 & 3 & 3 & 1 & 89.12 & 140.17 \\
14 & 2 & 1 & 2 & 404.81 & 331.30 & 32 & 3 & 3 & 2 & 288.53 & 299.60 \\
15 & 2 & 1 & 3 & 520.92 & 481.44 & 33 & 3 & 3 & 3 & 458.90 & 457.99 \\
16 & 2 & 2 & 1 & 112.45 & 149.95 & 34 & 3 & 4 & 1 & 86.34 & 110.46 \\
17 & 2 & 2 & 2 & 341.43 & 327.68 & 35 & 3 & 4 & 2 & 263.44 & 314.25 \\
18 & 2 & 2 & 3 & 491.98 & 487.77 & 36 & 3 & 4 & 3 & 437.74 & 471.13 \\
\hline
\end{tabular}

The ANOVA was carried out to verify if there is an influence in the main parameters and/or their interactions. The confidence interval of $95 \%$ was used. $F$-value or $p$-value (Table 4 ) can be used to identify which process parameters are statistically significant. Values lower $(p)$ or equal to 0.05 show that the main parameters or the interaction have significant effects on the response variable. The $R^{2}$ value indicates that the models fitted the data properly. Table 4 shows the ANOVA for cutting force. The main parameters tool, cutting speed and feed presented significant influence.

Table 4. Results of the analysis of variance for the cutting force.

\begin{tabular}{cccc}
\hline \multirow{2}{*}{ Process Parameters } & \multicolumn{3}{c}{ Cutting Force } \\
\cline { 2 - 4 } & SS & F-Value & $p$-Value \\
\hline Tool & 6436 & 5.89 & 0.006 \\
Cutting speed & 10,229 & 6.24 & 0.002 \\
Feed & $1,564,893$ & 1431.83 & 0.000 \\
Tool $\times$ Cutting speed & 2346 & 0.72 & 0.640 \\
Tool $\times$ feed & 1600 & 0.73 & 0.576 \\
Cutting speed $\times$ Feed & 1610 & 0.49 & 0.811 \\
Tool $\times$ Cutting speed $\times$ Feed & 388 & 0.06 & 1.000 \\
$R^{2}$ & $98.78 \%$ & - & - \\
\hline
\end{tabular}


Figure 9 illustrates the behavior of the cutting force as a function of the various levels used. The most influent parameter was the feed. The larger cutting efforts are necessary to remove larger amounts of material. The friction at the tool/chip and tool/workpiece interfaces is minimized with the use of coated tools, which proves that the lowest cutting force will be reached using the multilayer insert. Such a statement can also be confirmed by the results of tribological tests. As cited by Trent and Wright [33], when using the coating on cutting tools can be obtained lower forces.

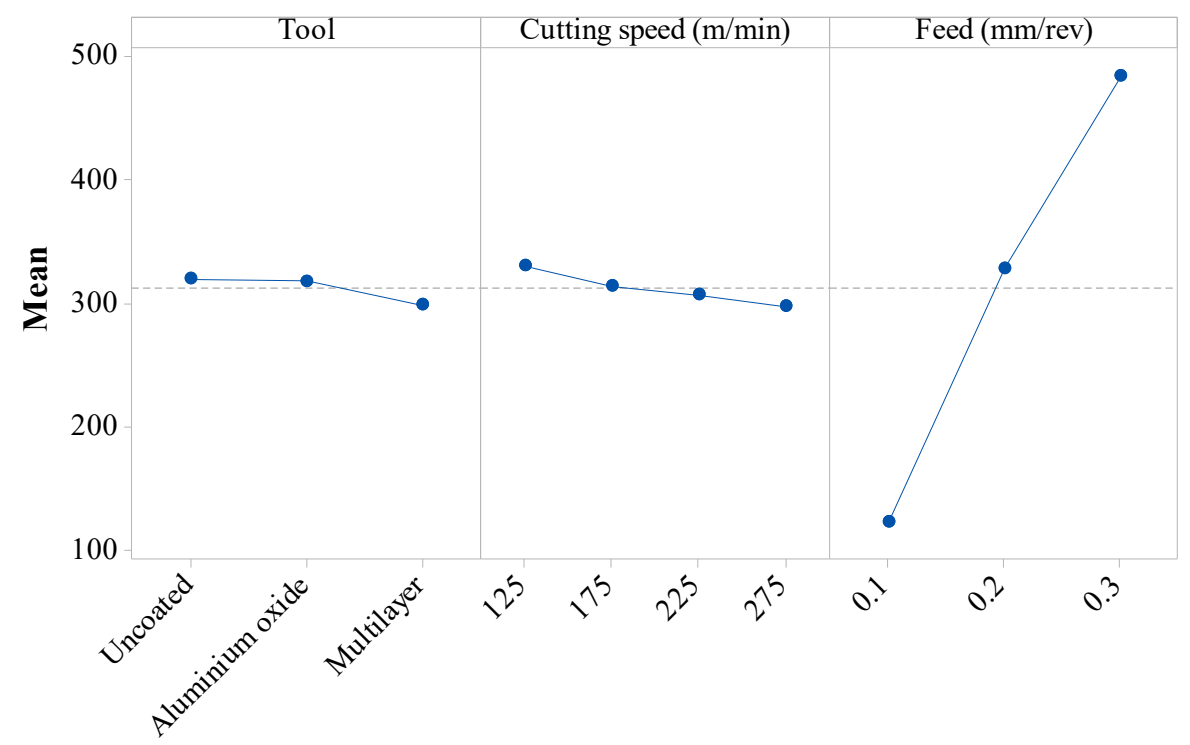

Figure 9. Influence of the main effects on the cutting force.

On the other hand, as the cutting speed increases, the cutting force tends to decrease as well. The relationship between the increase in cutting speed and the reduction in the coefficient of friction was stated by Puls et al. [34]. According to them, there is a displacement on the right side of the Stribeck curve, favoring the lubricant thickness between the materials in sliding. Higher cutting speeds cause greater heating in the cutting zone, changing the mechanical properties of the material, which requires less cutting power. Another factor to be highlighted is that the graphite acts as a lubricant between the tool and the workpiece, facilitating the shear, and consequently, contributing to the generation of lower cutting force.

\section{Conclusions}

Coatings characterization deposited by sol-gel was realized and the cutting force was measured during the CGI turning under various cutting conditions using uncoated and coated WC tools. The sol-gel method appears as a novel technique to improve the performance of the cutting tools. The principal results and conclusions can be pointed as:

- According to XRD analyses, the alumina coating deposited on the tool surfaces presented a crystalline structure corresponding to the $\mathrm{r}-\mathrm{Al}_{2} \mathrm{O}_{3}$ phase after the heat treatment step.

- The EDS confirmed the presence of the coatings and the thicknesses of the coatings have a micrometer scale $\left(\mathrm{Al}_{2} \mathrm{O}_{3}\right.$ and multilayer).

- According to the scratch test, the adhesion of the multilayer coating is higher than the one of the $\mathrm{Al}_{2} \mathrm{O}_{3}$ coating.

- The coated tools presented lower friction coefficients up to $100 \mathrm{~m}$. Besides, during the CGI cutting tests, the presence of graphite probably contributed to the reduction of friction due to the formation of a lubricating film.

- The ANOVA showed that the main parameter that influenced the resulting cutting force was the feed. The tool and cutting speed have minor influences. 
Author Contributions: Conceptualization, J.C.C.R.; design of the experiments, J.C.C.R; conducting of the experiments, B.A.R. and A.J.d.S.; conducting of the pin-on-disk tests, A.J.d.S. and M.A.C.; analysis of the data and writing of the paper, B.A.R., M.H., A.R.R. and J.C.C.R.; CGI foundry and workpiece analysis, D.J.d.C.; production of the sol-gel solution and deposition in cutting tools, B.A.R. and M.H.

Funding: This study was partly financed by the Coordenação de Aperfeiçoamento de Pessoal de Nível Superior-Brasil (CAPES)-Finance Code 001. We also gratefully acknowledge the agencies FAPEMIG (Fundação de Amparo à Pesquisa do Estado de Minas Gerais) and CNPq (Conselho Nacional de Desenvolvimento Científico e Tecnológico) for providing financial support.

Conflicts of Interest: The authors declare no conflict of interest.

\section{References}

1. Gouveia, R.M.; Silva, F.J.G.; Reis, P.; Baptista, A.P.M. Machining duplex stainless steel: comparative study regarding end mill coated tools. Coatings 2016, 6, 51. [CrossRef]

2. Tooptong, S.; Park, K.-H.; Kwon, P. A comparative investigation on flank wear when turning three cast irons. Tribol. Int. 2018, 120, 127-139. [CrossRef]

3. Stylianou, R.; Tkadletz, M.; Schalk, N.; Penoy, M.; Czettl, C.; Mitterer, C. Effects of reference materials on texture coefficients determined for a CVD $\alpha-\mathrm{Al}_{2} \mathrm{O}_{3}$ coating. Surf. Coat. Technol. 2019, 359, 314-322. [CrossRef]

4. Pulci, G.; Tirillò, J.; Marra, F.; Sarasini, F.; Bellucci, A.; Valente, T.; Bartuli, C. High temperature oxidation of MCrAlY coatings modified by $\mathrm{Al}_{2} \mathrm{O}_{3}$ PVD overlay. Surf. Coat. Technol. 2015, 268, 198-204. [CrossRef]

5. Yang, K.; Chen, J.; Hao, F.; Liu, C.; Tao, S.; Ding, C. Stress-induced phase transformation and amorphous-to-nanocrystalline transition in plasma-sprayed $\mathrm{Al}_{2} \mathrm{O}_{3}$ coating with relative low temperature heat treatment. Surf. Coat. Technol. 2014, 253, 277-283. [CrossRef]

6. Chen, Y.-C.; Ai, X.; Huang, C.-Z.; Wang, B.-Y. Preparation of $\alpha$-alumina coated carbide tools by the sol-gel process. Mater. Sci. Eng. A 2000, 288, 19-25. [CrossRef]

7. Pereira, N.; Rubio, J.C.C.; Santos, A.J.; Houmard, M.; Câmara, M.A.; Rodrigues, A.R. Drilling of nodular cast iron with a novel $\mathrm{SiO}_{2}$ coating deposited by sol-gel process in HSS drill. Int. J. Adv. Manuf. Technol. 2019, in press. [CrossRef]

8. Astakhov, V.P. Tribology of Metal Cutting, 1st ed.; Elsevier: Oxford, UK, 2006.

9. Rubio, J.C.C.; Rezende, B.A.; Vieira, L.M.G.; Romero, H.M.; Brenes, L.A.R. Comparative study on lubricating and cooling conditions in the drilling process of electrolytic copper. Int. J. Adv. Manuf. Technol. 2019, 101, 2633-2641. [CrossRef]

10. Rao, J.; Sharma, A.; Rose, T. Titanium aluminium nitride and titanium boride multilayer coatings designed to combat tool wear. Coatings 2018, 8, 12. [CrossRef]

11. Dobrzański, L.A.; Skrzypek, S.; Pakuła, D.; Mikuła, J.; Křiž, A. Influence of the PVD and CVD technologies on the residual macro-stresses and functional properties of the coated tool ceramics. J. Achiev. Mater. Manuf. Eng. 2009, 35, 162-168.

12. Rubio, J.C.C.; Rezende, B.A.; Vieira, L.M.G.; Houmard, M. Drilling of aluminium/PE sandwich material with a novel $\mathrm{TiO}_{2}$-coated HSS drill deposited by sol-gel process. Int. J. Adv. Manuf. Technol. 2017, 92, 1567-1577.

13. Tlili, B.; Barkaoui, A.; Walock, M. Tribology and wear resistance of the stainless steel. The sol-gel coating impact on the friction and damage. Tribol. Int. 2016, 102, 348-354. [CrossRef]

14. Wright, J.D.; Sommerdijk, N.A.J.M. Sol-Gel Materials: Chemistry and Applications, 1st ed.; Gordon and Breach Science Publishers: Amsterdam, The Netherlands, 2001.

15. Dai, W.X.; Chen, X.; Li, E.; Wang, X.X.; Liu, P.; Fu, X.Z. Influence of $\mathrm{pH}$ value of $\mathrm{TiO}_{2}$ sol on surface gloss of corresponding $\mathrm{TiO}_{2}$ film coated on ceramic tiles. Surf. Eng. 2009, 25, 106-110. [CrossRef]

16. Brinker, C.J.; Scherer, G.W. Sol-Gel Science: The Physics and Chemistry of Sol-Gel Processing; Academic Press: Boston, MA, USA, 1990.

17. Yang, S.; Zhang, Y.; Mo, D. Spectroscopic ellipsometry studies of sol-gel-derived Cu-doped ZnO thin films. Thin Solid Films 2014, 571, 605-608. [CrossRef]

18. Schneller, T.; Waser, R.; Kosec, M.; Payne, D. Chemical Solution Deposition of Functional Oxide Thin Films; Springer: Wien, Austria, 2013.

19. Czettl, C.; Pohler, M. Progress in development of coated indexable cemented carbide inserts for machining of iron based work piece materials. IOP Conf. Ser. Mater. Sci. Eng. 2016, 119, 012011. [CrossRef] 
20. Toma, F.L.; Stahr, C.C.; Berger, L.M.; Saaro, S.; Herrmann, M.; Deska, D.; Michael, G. Corrosion resistance of APS- and HVOF-sprayed coatings in the $\mathrm{Al}_{2} \mathrm{O}_{3}-\mathrm{TiO}_{2}$ system. J. Therm. Spray Technol. 2010, 19, 137-147. [CrossRef]

21. Gurylev, V.; Su, C.-Y.; Perng, T.-P. Surface reconstruction, oxygen vacancy distribution and photocatalytic activity of hydrogenated titanium oxide thin film. J. Catal. 2015, 330, 177-186. [CrossRef]

22. Du, X.; Men, K.; Xu, Y.; Li, B.; Yang, Z.; Liu, Z.; Li, L.; Li, L.; Feng, T.; Rehman, W.U.; et al. Enhanced capacitance performance of $\mathrm{Al}_{2} \mathrm{O}_{3}-\mathrm{TiO}_{2}$ composite thin film via sol-gel using double chelators. J. Colloid Interface Sci. 2015, 443, 170-176. [CrossRef]

23. Su, G.; Guo, Y.; Song, X.; Tao, H. Effects of high-pressure cutting fluid with different jetting paths on tool wear in cutting compacted graphite iron. Tribol. Int. 2016, 103, 289-297. [CrossRef]

24. Abdoos, M.; Yamamoto, K.; Bose, B.; Fox-Rabinovich, G.; Veldhuis, S. Effect of coating thickness on the tool wear performance of low stress TiAIN PVD coating during turning of compacted graphite iron (CGI). Wear 2019, 422-423, 128-136. [CrossRef]

25. Yamamoto, K.; Abdoos, M.; Paiva, J.M.; Stolf, P.; Beake, B.; Rawal, S.; Fox-Rabinovich, G.; Veldhuis, S. Cutting performance of low stress thick TiAlN PVD coatings during machining of compacted graphite cast iron (CGI). Coatings 2018, 8, 38. [CrossRef]

26. Heep, T.; Bickert, C.; Abele, E. Application of carbon dioxide snow in machining of CGI using an additively manufactured turning tool. J. Manuf. Mater. Process. 2019, 3, 15. [CrossRef]

27. ASTM A842-85 (2009). Standard Specification for Compacted Graphite Iron Castings; ASTM International: West Conshohocken, PA, USA, 2009.

28. Houmard, M.; Vasconcelos, D.C.L.; Vasconcelos, W.L.; Berthomé, G.; Joud, J.C.; Langlet, M. Water and oil wettability of hybrid organic-inorganic titanate-silicate thin films deposited via a sol-gel route. Surf. Sci. 2009, 603, 2698-2707. [CrossRef]

29. ASTM G99-05 (2010). Standard Test Method for Wear Testing with a Pin-on-Disk Apparatus; American Society for Testing and Materials: Philadelphia, PA, USA, 2010.

30. Langlet, M.; Permpoon, S.; Riassetto, D.; Berthomé, G.; Pernot, E.; Joud, J. Photocatalytic activity and photo-induced superhydrophilicity of sol-gel derived $\mathrm{TiO}_{2}$ films. J. Photochem. Photobiol. A Chem. 2006, 181, 203-214. [CrossRef]

31. Aun, D.P.; Houmard, M.; Mermoux, M.; Latu-Romain, L.; Joud, J.; Berthomé, G.; Buono, V.T.L. Development of a flexible nanocomposite $\mathrm{TiO}_{2}$ film as a protective coating for bioapplications of superelastic NiTi alloys. Appl. Surf. Sci. 2016, 375, 42-49. [CrossRef]

32. Kalpakjian, S.; Schimd, S.R. Manufacturing Engineering and Technology, 6th ed.; Prentice Hall: Upper Saddle River, NJ, USA, 2010.

33. Trent, E.M.; Wright, P.K. Metal Cutting, 4th ed.; Butterworth Heinemann: Woburn, MA, USA, 2000.

34. Puls, H.; Klocke, F.; Lung, D. Experimental investigation on friction under metal cutting conditions. Wear 2014, 310, 63-71. [CrossRef]

(C) 2019 by the authors. Licensee MDPI, Basel, Switzerland. This article is an open access article distributed under the terms and conditions of the Creative Commons Attribution (CC BY) license (http://creativecommons.org/licenses/by/4.0/). 